
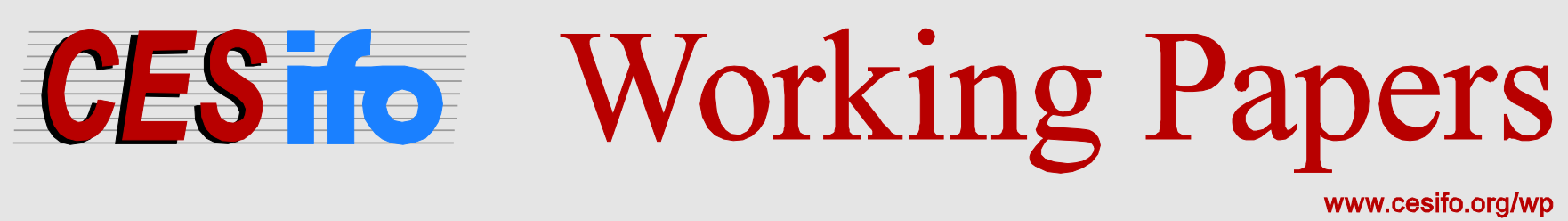

\title{
Financing Public Capital through Land Rent Taxation: A Macroeconomic Henry George Theorem
}

\author{
Linus Mattauch \\ Jan Siegmeier \\ Ottmar Edenhofer \\ Felix Creutzig
}

CESIFO WORKING PAPER NO. 4280

CATEgory 1: Public FinANCE

JUNE 2013

An electronic version of the paper may be downloaded

- from the SSRN website:

- from the RePEc website:

- from the CESifo website:

www.SSRN.com

Www.RePEc.org

www.CESifo-group.org/wp

\section{CESifo}




\title{
Financing Public Capital through Land Rent Taxation: A Macroeconomic Henry George Theorem
}

\begin{abstract}
Financing productive public capital through distortionary taxes typically creates a trade-off: the optimal investment is determined as a compromise between efficiency-enhancing public investment and perturbing market efficiency, but is never socially optimal. In contrast, such a trade-off can often be avoided if public capital is financed by taxing rents of a fixed production factor, such as land. Here, we provide a macroeconomic version of the Henry George Theorem. Specifically, we prove that the socially optimal level of the public capital stock can be reached by a land rent tax, provided land is a more important production factor than public capital.
\end{abstract}

JEL-Code: H210, H400, H540, Q240.

Keywords: land rent tax, public investment, Henry George Theorem, social optimum.

\author{
Linus Mattauch \\ Mercator Research Institute on Global \\ Commons and Climate Change \\ Torgauer Str. 12-15 \\ Germany-10829 Berlin \\ mattauch@mcc-berlin.net \\ Ottmar Edenhofer \\ Potsdam Institute for Climate Impact \\ Research \\ Potsdam / Germany \\ ottmar.edenhofer@pik-potsdam.de
}

\author{
Jan Siegmeier \\ Technical University of Berlin \\ Berlin / Germany \\ jan.siegmeier@mailbox.tu-berlin.de \\ Felix Creutzig \\ Mercator Research Institute on Global \\ Commons and Climate Change \\ Berlin / Germany \\ creutzig@mcc-berlin.net
}

May 24, 2013 


\section{Introduction}

Public capital is a key determinant of aggregate productivity (Romp and De Haan, 2007): productivity increases may stem from investments into physical infrastructure, but also into the health and the education system or into the stock of publicly available knowledge. However, collecting revenue for public investment through taxation usually creates inefficient allocations. For instance, economic growth decreases if capital income or output is taxed (Barro, 1990; Barro and Sala-I-Martin, 1992). Typically, a trade-off between productivity growth from public investment and efficiency loss from taxation is identified, which determines the best possible level of public investment. It is lower than the socially optimal level, which thus cannot be reached by fiscal policy when lump-sum taxation is infeasible.

In this article, we examine a case in which such a trade-off does not exist: public investment is financed by taxing rents from fixed factors of production such as land. We prove that if the land rent is higher than the socially optimal level of public investment, taxing the rent and investing the revenue in public capital is a socially optimal policy. This result can be considered as a dynamic and macroeconomic analogue to the "Henry George Theorem" or the "golden rule" of local public finance.

Our argument is based on two premises. First, we assume that public investment is productivity-enhancing ${ }^{1}$, be it in the form of infrastructure (Barro, 1990; Gramlich, 1994), research and development (Romer, 1990) or investment into "human capital" via education or the health system (Glomm and Ravikumar, 1992; Bloom et al., 2004). The nature of the investment may differ according to the state of a country's economy: In developing countries, building new infrastructures and public capital stocks would enhance productivity (Agénor, 2013). In developed countries, maintaining the existing, but deteriorating infrastructures requires public investment. Moreover, transforming infrastructures is required for overcoming the lockin into carbon-intensive production processes to mitigate global warming and its economic damages (Unruh, 2000; Davis et al., 2010; Lehmann et al., 2012; Mattauch et al., 2012).

Second, we also assume that fixed factors are relevant for the production process: In fact the rents on non-reproducible factors such as land are a highly significant share of total economic output (Caselli and Feyrer, 2007). Furthermore, while our model assumes that taxing land rents is nondistortionary, our results translate to settings in which it is distortionary, but beneficial (as in Edenhofer et al. (2013); see Section 6.2).

\footnotetext{
${ }^{1}$ For a review of the theoretical literature of the link between government spending and growth, see Irmen and Kuehnel (2009). Empirical reviews of this premise are provided by Romp and De Haan (2007), Zagler and Dürnecker (2003) and Creel and Poilon (2008).
} 
Our result is related to the Henry George Theorem, which states that local land rents equal expenditure on a local public good provided the population size is optimal (Arnott and Stiglitz, 1979; Arnott, 2004). Its consequence is that a single land rent tax is sufficient to finance a local public good. This theorem considers a static relationship and has chiefly been applied in the context of urban economics. Our result concerns the dynamics of relevant capital stocks and should be seen as a dynamic and macroeconomic analogue: If land is an important production factor, the land rent is sufficient to finance the socially optimal public capital level provided that the accumulation of private capital is optimal. If instead of land rents, firms' profits arising from public investment are considered, those profits are in turn sufficient to finance the optimal level of public investment under optimal capital accumulation.

In the following, we extend the neoclassical model of economic growth to include public capital and land as factors of production. In Section 2, we consider the socially optimal allocation in such a model. For a Cobb-Douglas production function, a formula for the socially optimal public investment in terms of the land rent is given. In Section 3, we study the corresponding decentralized equilibrium and prove that financing public investment by a tax on land rent reproduces the social optimum, provided the land rent is sufficiently high. In Section 4, we consider a variant of the model: If firms make profits, a direct analogue to the Henry George Theorem can be obtained. In Section 5, we introduce technological progress and show that if it permits a balanced growth path, the above results still hold. If no balanced growth path exists, factor shares may change depending on the production function. In Section 6, we discuss modifications, extensions and the empirical relevance of our results.

In the context of urban economics, a dynamic Henry George Theorem has been introduced by Fu (2005) and Kawano (2012) for studying transition phenomena of cities. It extends the Henry George Theorem by considering the present-value of future public investments and land rents under the usual condition of optimal population size. Our extension of the theorem is different as it considers its translation to optimal capital accumulation instead of optimal population size and thus to a macroeconomic setting. The relationship between the land price, the land rent and the interest rate has been captured as a (no-)arbitrage condition in growth models by Feldstein (1977), Calvo et al. (1979), Burgstaller (1994) and Foley and Michl (1999). Our study adopts their treatment of the production factor land in a growth model. 


\section{Socially optimal allocation: a macroeconomic Henry George formula}

We describe the structure of the economy, find the socially optimal allocation and determine the relationship between land and public investment in the steady-state. In the economy, output $Y$ depends on a private capital stock $K$, a public capital stock $G$ and on land $\bar{S}$ :

$$
Y_{t}=F\left(G_{t}, K_{t} ; \bar{S}\right)
$$

The production function fulfills the conventional assumptions that $F_{S}, F_{G}$, $F_{K}>0$, but $F_{S S}, F_{G G}, F_{K K}<0$, where $F_{S}:=\frac{\mathrm{d} F}{\mathrm{~d} S}\left(K_{t}, G_{t} ; \bar{S}\right)$ etc. The total land $\bar{S}$ is constant over time, so the social planner seeks the optimal distribution of private capital $K$ and public capital $G$. Unless noted otherwise, it is assumed that the production function is linearly homogenous in capital and land. Output is divided between consumption $C_{t}$ and investment into the two capital stocks, which have depreciation rates $\delta_{k}$ and $\delta_{g}$ respectively. The social planner chooses consumption $C_{t}$ and investment into public capital $I_{g t}$ to maximize the welfare of an infinitely-lived representative household with instantaneous utility given by $U(C)=\frac{C^{(1-\eta)}-1}{1-\eta}$. The maximization problem of the social planner is thus

$$
\begin{array}{ll} 
& \max _{C_{t}, I_{g t}} \int_{t=0}^{\infty} U\left(C_{t}\right) e^{-\rho t} d t \\
\text { s.t. } & \dot{K}_{t}=F\left(K_{t}, G_{t} ; \bar{S}\right)-C_{t}-I_{g t}-\delta_{k} K_{t} \quad \text { and } \\
& \dot{G}_{t}=I_{g t}-\delta_{g} G_{t} .
\end{array}
$$

The maximization problem is completed by initial conditions $\left(K(0)=K_{0}\right.$, $\left.G(0)=G_{0}\right) .^{2}$ Solving the maximization problem by standard optimal control theory yields a Keynes-Ramsey rule for $K$ and $G$ :

$$
\frac{\dot{C}_{t}}{C_{t}}=\frac{1}{\eta}\left[F_{K}\left(K_{t}, G_{t}\right)-\rho-\delta_{k}\right]
$$

and similarly

$$
\frac{\dot{C}}{C}=\frac{1}{\eta}\left[F_{G}\left(K_{t}, G_{t}\right)-\rho-\delta_{g}\right]
$$

which implies

$$
F_{K}-\delta_{k}=F_{G}-\delta_{G}
$$

In the (non-trivial and saddle-point stable) steady state $\left(K^{*}, G^{*}, C^{*}, I_{g}^{*}\right)$ of the model, Equations (2), (3), (4) and (5) are zero. Thus the steady-state

\footnotetext{
${ }^{2}$ Land is not a state variable of the optimization: It is assumed that all land is always productive and that its use has no opportunity costs.
} 
is characterized by the equations:

$$
\begin{aligned}
F_{K}^{*}=F_{K}\left(K^{*}, G^{*} ; \bar{S}\right) & =\rho+\delta_{k} \\
F_{G}^{*}=F_{G}\left(K^{*}, G^{*} ; \bar{S}\right) & =\rho+\delta_{g} \\
F\left(K^{*}, G^{*} ; \bar{S}\right) & =C^{*}+I_{g}^{*}+\delta_{k} K^{*} \\
I_{g}^{*} & =\delta_{g} G^{*} .
\end{aligned}
$$

\subsection{A macroeconomic Henry George Formula}

In the following a relation between the optimal public investment $I_{g}^{*}$ and the land rent $R:=F_{S} \cdot \bar{S}$ in the steady state will be derived. To this end a specific functional form needs to be assumed: Suppose that the production function has Cobb-Douglas form

$$
F(K, G ; \bar{S})=G^{\beta} K^{\alpha} \bar{S}^{1-\alpha},
$$

with $0<\alpha, \beta<1$ which implies

$$
F_{G}=\beta \frac{Y}{G} .
$$

The land rent $R$ is thus given by

$$
R=F_{S}\left(K_{t}, G_{t}, \bar{S}\right) \cdot \bar{S}=(1-\alpha) Y .
$$

Proposition 1 (Simple Macroeconomic Henry George Formula). Suppose production can be described by a Cobb-Douglas function with factors of production private and public capital as well as land and assume that production has constant returns to scale in land and private capital. Then, in the steady state of the socially optimal allocation, the investment in public capital is related to the land rent as follows:

$$
I_{g}^{*}=\frac{\delta_{g}}{\rho+\delta_{g}} \frac{\beta}{1-\alpha} R .
$$

When is the land rent greater than the socially optimal amount of public investment? The result has the intuitive interpretation that if the national income share of land is greater than that of the public capital stock, the socially optimal investment in public capital is lower than the land rent (assuming that the first factor is approximately equal to one).

Proof. We exploit the steady-state relationships. By Equations (10) and (12),

$$
I_{g}^{*}=\delta_{g} \beta \frac{Y^{*}}{F_{G}^{*}} .
$$

To eliminate $F_{G}^{*}$, Equation (8) is used

$$
I_{g}^{*}=\frac{\delta_{g}}{\delta_{g}+\rho} \beta Y^{*} .
$$

Inserting Equation (13) yields the claimed formula. 


\section{Decentralized equilibrium: Land rent taxation reproduces the social optimum}

In this section the decentralized equilibrium corresponding to the social planner solution is introduced (Section 3.1) and the main result of the article is proved: financing public investment by a tax on the land rent reproduces the social optimum if the land rent is sufficiently high (Section 3.2).

\subsection{The economy}

The decentralized version of the economy consists of two stock markets for capital and land and one flow market for the final consumption good. We detail the role of the households, the firms and the government in turn.

\subsubsection{Households}

The economy is populated by a continuum of homogenous households, whose behavior can be described by a representative household. It seeks to maximize its intertemporal utility $V=\int_{0}^{\infty} U\left(C_{t}\right) e^{-\rho t} \mathrm{~d} t$, with $U(C)=\frac{C^{1-\eta}-1}{1-\eta}$, subject to its budget constraint:

$$
\dot{K}_{t}+p_{t} \dot{\bar{S}}+C_{t}=r_{t} K_{t}+l_{t} \bar{S} .
$$

Here $p_{t}$ denotes the land sales price, $l_{t}$ the land rental price and $r_{t}$ the interest rate. Initial conditions $K_{0}=K(0)$ and $G_{0}=G(0)$ and a transversality condition $^{3}$ are observed. Income from renting out capital and land can be spent on consumption, invested in capital or used to (potentially) increase the land assets. Although total land is fixed and homogenous households do not trade land among them, it makes sense to introduce a land market in this way because it yields a price for the asset, reflecting households' wealth even if land is not actually traded (see also Section 6.2).

Solving the intertemporal control problem, the behavior of the household is captured by two first-order conditions: A (no-)arbitrage condition

$$
r_{t}=\frac{l_{t}}{p_{t}}+\frac{\dot{p_{t}}}{p_{t}}
$$

and the Keynes-Ramsey Equation:

$$
\frac{\dot{C}_{t}}{C}=\frac{1}{\eta}(r-\rho)
$$

\footnotetext{
${ }^{3}$ The appropriate transversality condition is:

$$
\lim _{t \rightarrow \infty}[k(t)+p(t) \bar{S}] e^{-\xi(t)}=0
$$$$
\text { with } \xi(t) \equiv \int_{0}^{t} r(\tilde{t}) \mathrm{d} \tilde{t} \text {. }
$$ 
Solving the arbitrage condition (18) for $p_{t}$ shows that the land price is equal to the net present value of all future land rent income.

\subsubsection{Firms}

The production sector consists of a representative firm, whose profit maximization problem and resulting first-order conditions are standard. With $\tilde{r}_{t}=r_{t}-\delta_{k}$, profit maximization

$$
\max _{K, S} F\left(K_{t}, \bar{S} ; G_{t}\right)-\tilde{r}_{t} K_{t}-l_{t} \bar{S}
$$

implies the standard first-order conditions

$$
\tilde{r}_{t}=F_{K}\left(K_{t}, \bar{S} ; G_{t}\right)
$$

and

$$
l_{t}=F_{S}\left(K_{t}, \bar{S} ; G_{t}\right) .
$$

Using the constant returns to scale assumption in $K$ and $S$, it follows that $F\left(K_{t}, \bar{S} ; G_{t}\right)=F_{K} \cdot K+F_{S} \cdot \bar{S}$ and thus the firm's profit is zero.

\subsubsection{Government}

The government finances the provision of the public capital stock $G$ with the tax revenue $T$ :

$$
\dot{G}_{t}=T-\delta_{g} G_{t}
$$

For possibilities of revenue collection, see Section 3.2.

\subsubsection{Equilibrium}

The decentralized equilibrium converges to a steady-state for all possibilities of tax collection discussed below ${ }^{4}$. The steady-state value $K^{M}$ of the decentralized equilibrium may be lower than the socially optimal value $K^{*}$ for two reasons: First, the government may not mobilize the resources for providing the socially optimal steady-state level of public capital $G$. Second, it may mobilize the resources in a distortionary way, that is, although the steady-state level of $G$ is socially optimal, the distribution of capital and consumption may not be optimal.

\footnotetext{
${ }^{4}$ The dynamics of the system are captured by Equations (17), (18), (19) and (22). The steady state is a saddle point with one stable path, as can be shown by linearizing around it. The economic system is on that stable path because $C$ is a jump variable that instantaneously conforms to the optimality and transversality conditions.
} 


\subsection{Land rent taxation reproduces the social optimum}

In this subsection, the consequences of levying different taxes for financing public capital in the steady-state are examined: a tax on land rent or on land value permit to reproduce the social optimum if the land rent is sufficiently high. A capital or an output tax are distortionary and hence cannot reproduce it. Lump-sum taxation is excluded from the spectrum of possibilities as it is politically infeasible. In the following the superscript ${ }^{M}$ stands for the steady-state value of the respective variable from the market model and an asterisk * for its steady-state value from the social planner model.

Theorem 2 (Land rent taxation reproduces the social optimum). A land rent tax allows to reproduce the social optimum if the land rent is sufficient to finance the optimal public investments.

Corollary 3 (Land value taxation). A tax on land value allows to reproduce the social optimum if the land value is sufficiently high to finance the socially optimal public investment.

Proof of Theorem 2. With a land rent tax $\tau$, the tax revenue is $T=\tau l_{t} S_{t}$. The budget constraint of the household (17) becomes

$$
\dot{K}_{t}+p_{t} \dot{\bar{S}}_{t}+C_{t}=r_{t} K_{t}+(1-\tau) l_{t} S_{t} .
$$

Assume that the land rent is sufficient to fully finance the public good: the government can set the $\operatorname{tax} \tau$ such that

$$
T=\tau l_{t} \bar{S}=I_{g}^{*}=\delta_{g} G^{*}
$$

(If a Cobb-Douglas production function as in Equation (11) is assumed then by Proposition 1, the tax rate needs to be $\tau=\frac{\delta_{g}}{\rho+\delta_{g}} \frac{\beta}{1-\alpha}$.) The tax does not affect the Keynes-Ramsey Equation (19), so it follows that $r_{t}=\rho$. As $G^{M}=G^{*}$, also $F_{K}^{M}(K, G, \bar{S})=F_{K}^{S}(K, G, \bar{S})$. Thus, it also holds that $K^{M}=K^{S}$. It remains to verify $C^{M}=C^{*}$ to show that the decentralized equilibrium reproduces the social optimum:

$$
\begin{aligned}
C^{M} & =r^{M} K^{M}+(1-\tau) l^{M} \bar{S} \\
& =r^{M} K^{M}+l^{M} \bar{S}-I_{g}^{*} \\
& =\left(F_{K}^{M}-\delta_{k}\right) K^{M}+F_{S}^{M} \bar{S}-I_{g}^{*} \\
& =F_{K}^{*} K^{*}+F_{S}^{*} \bar{S}-\delta_{k} K^{*}-I_{g}^{*} \\
& =F\left(K^{*}, G^{*}, \bar{S}\right)-\delta_{k} K^{*}-I_{g}^{*} \\
& =C^{*}
\end{aligned}
$$

as required. 
Proof of Corollary 3. For a property tax $\tau$, the tax revenue amounts to $T=$ $\tau p_{t} \bar{S}$ and the budget constraint of the household (17) becomes

$$
\dot{K}_{t}+p_{t} \dot{\bar{S}}_{t}+C_{t}=r_{t} K_{t}+l_{t} S_{t}+\Pi_{t}-\tau p_{t} \bar{S}_{t}
$$

Similarly to the previous proof, it can be shown that the aggregate variables are at the socially optimal level. However, the arbitrage condition is modified as one obtains for this case that:

$$
r=\frac{l}{p}+\frac{\dot{p}}{p}-\tau .
$$

If the land rent is lower than public investments, another tax income source has to be mobilized. For these, the usual results about taxation in a Ramsey model apply: Capital and output taxation cannot reproduce the social optimum as they are distortionary ((Groth, 2011, ch.11), (Acemoglu, 2008 , ch.8)). Thus, if no other non-distortionary possibilities for taxation exist, the usual trade-off between productivity-enhancing investment in the public capital stock and distortionary taxation exists again for the part of investment need that exceeds the land rent.

\section{Dynamizing the Henry George Theorem: Tax- ing firms' profits instead of the land rent}

In this section we elaborate on the kinship of the main result of the present article and the Henry George Theorem of public finance. The theorem states that "with identical individuals, in a city of optimal population size, differential land rents (the aggregate over the city of urban land rent less the opportunity cost of land in non-urban use) equal expenditure on pure local public goods" (Arnott, 2004, p.1057). This means that confiscating the entire land rent - a Georgist "single tax" - is sufficient to finance any level of the public good, whether socially optimal or not. The theorem is a very general relationship that has been discovered in different forms independently by several scholars. We are here concerned with its simplest version, proved by Stiglitz (1977), that considers profits instead of land rents: it is socially optimal to use the total profit in a static urban economy to finance a local public good provided the population size is optimal (see also: (Atkinson and Stiglitz, 1980, p.522-525), Arnott and Stiglitz (1979)).

So far the analogy to our result has been that a single (land) rent tax is necessary and (sometimes) sufficient to finance the optimal public good or investment, respectively, under the modification that the macroeconomic setting requires optimal capital accumulation instead of optimal population size. In this section we demonstrate that the analogy can be even closer: If 
not land, but firms' profits are considered, the Henry George Theorem has the additional feature that the benefit of the public good is fully captured in firms' profits. This partially carries over to a growth model in which the public and the private capital stocks are optimal - although the benefit of the public capital stock is then not fully captured by profits, these are sufficient to finance the optimal investment. Because of the dynamic context, the pure rate of time preference causes the profit to be higher than the required optimal public investment (as Proposition 4 will show).

To demonstrate the analogy, we consider a slightly modified model. Assume for this section that the production function is linearly homogenous in all three arguments: public capital, private capital and land (in fact land is inessential to the argument). The provision of public capital by the government results in a positive externality that allows firms to make profit $\Pi_{t}$ under this functional form. ${ }^{5}$

$$
\Pi_{t}=F\left(K_{t}, \bar{S} ; G_{t}\right)-R_{t} K_{t}-l_{t} \bar{S}=F_{G}\left(K_{t}, \bar{S} ; G_{t}\right) G_{t} .
$$

These profits can be taxed to finance public expenditure:

Proposition 4 (Macroeconomic Analogue of Stiglitz' Henry George Theorem). In the steady-state, the social optimum can be implemented by taxing firms' profits. The tax rate on profits is $\tau=\frac{\delta_{g}}{\delta_{g}+\rho}$.

In Stiglitz' result $\tau=1$. In our dynamic setting a non-zero rate of pure time preference $\rho$ causes $\tau<1$. This reflects that in neoclassical growth models the optimal capital stock does not maximize instantaneous consumption. If in Equation (8) no $\rho$ appeared, then the analogy would be complete ${ }^{6}$.

Proof. With a tax on profits, tax revenue is $T=\tau \Pi_{t}$ and the budget constraint of the household (17) becomes

$$
\dot{K}_{t}+p_{t} \dot{S}_{t}+C_{t}=r_{t} K_{t}+l_{t} S_{t}+(1-\tau) \Pi_{t}
$$

The tax does not affect the first-order conditions. Assuming for the moment that the tax revenue from taxing profits is sufficient to finance the socially optimal level of $G^{*}$ :

$$
T=\tau \Pi_{t}=I_{g}^{*}=\delta_{g} G^{*} .
$$

\footnotetext{
${ }^{5}$ This is a credible assumption for some public investments, such as technology parks. However the focus of this section is on highlighting the close kinship of our results with the Henry George Theorem, not on exploring which assumptions concerning the impact of public investments on the economy are most realistic.

${ }^{6}$ Stiglitz' Henry George Theorem is valid even if the local public good is not of optimal size (that is, if the corresponding Samuelson condition is violated). In the model under discussion, it is not the case that for arbitrary production functions and any level of $G$, a profit tax would fully finance it because the stock of private capital may be too small so that $F_{G}(K, G ; \bar{S})>\delta_{g}$.
} 
It can then be verified with arguments similar to those in the proof of Theorem 2 that all aggregate variables of the decentralized equilibrium have their socially optimal steady-state values. For instance, for consumption:

$$
\begin{aligned}
C^{M} & =r_{t} K^{M}+l_{t} \bar{S}+(1-\tau) \Pi_{t} \\
& =F\left(K^{*}, S^{*}, G^{*}\right)-\delta_{k} K^{* S}-I_{g}^{*} \\
& =C^{*} .
\end{aligned}
$$

Thus the steady state of the market solution is socially optimal. However, in this case $F_{G}(K, G ; \bar{S})=\delta_{g}+\rho$, by Equation (8). Thus

$$
\Pi_{t}=F_{G}\left(K^{*}, G^{*} ; \bar{S}\right) G^{*}=\left(\delta_{g}+\rho\right) G^{*} .
$$

Combining Equations (30) and (32) yields

$$
\tau\left(\delta_{g}+\rho\right) G^{*}=\delta_{g} G^{*} .
$$

Hence

$$
\tau=\frac{\delta_{g}}{\delta_{g}+\rho}<1
$$

\section{Labor- and land-augmenting technological progress}

The purpose of adding technological progress to the previously discussed model is twofold: we first show that the previous results are robust under technological progress provided the economy is on a balanced growth path. We then highlight that outside the balanced growth path, factor shares may change depending on the production function. This result is significant for the present study as the condition for feasibility of the social optimum (in Proposition 1) depends on the factor share of land. It may also permit to evaluate the validity of some claims first enunciated by Henry George concerning the significance of the land rent.

\subsection{Balanced growth}

The model is extended to include labor $L_{t}$ as an additional input to production and technological progress in land and labor productivity. The available labor force evolves at a constant exogenous rate $n$, so $\dot{L}_{t} / L_{t}=n$. The productivities of labor and land grow at exogenous rates $A_{L t}$ and $A_{S t}$. The production function considered in this section is thus

$$
Y_{t}=F\left(K_{t}, G_{t}, A_{S t} \bar{S}, A_{L t} L_{t}\right)
$$

In the following, only exponential productivity growth is considered: define constants $g_{l}=\dot{A}_{L t} / A_{L t}$ and $g_{s}=\dot{A}_{S t} / A_{S t}$. Then, for general production 
functions, both the socially optimal allocation and the decentralized equilibrium only permit a balanced growth path if productivity growth in land and in labor satisfies the following condition:

Lemma 5. The socially optimal allocation and the decentralized equilibrium permit a balanced growth path if and only if

$$
g_{s}=g_{l}+n .
$$

Proof. Normalizing all variables with respect to effective labor $A_{L t} L$ and denoting them by small letters, one obtains the Keynes-Ramsey rule

$$
\frac{\dot{c_{t}}}{c_{t}}=\frac{1}{\eta}\left(f_{k t}\left(k_{t}, g_{t}, s_{t}\right)-\delta_{k}-\tilde{\rho}-g_{l}-n\right) .
$$

Here $\tilde{\rho}$ is a modified discount rate: $\tilde{\rho}=\rho-(1-\eta) g_{s}$. Hence the growth rate of consumption is only zero if $f_{k} t\left(k_{t}, g_{t}, s_{t}\right)$ is constant. This is only true if $s_{t}$ is constant, which is the case if and only if $A_{S t}=e^{n t} A_{L t}$ or $g_{s}=\left(\dot{A_{L}} e^{n t}+n A_{L} e^{n t}\right) /\left(A_{L} e^{n t}\right)=g_{l}+n$.

Under this condition, the balanced growth path is given by

$$
\frac{\dot{C}_{t}}{C_{t}}=\frac{\dot{Y}_{t}}{Y_{t}}=\frac{\dot{K}_{t}}{K_{t}}=\frac{\dot{G}_{t}}{G_{t}}=\frac{\dot{I}_{g t}}{I_{g t}}=g_{l}+n
$$

Our central results hold with modifications under balanced technological progress. To show this first for the socially optimal allocation, assume specifically a Cobb-Douglas production function

$$
F\left(K_{t}, G_{t}, A_{S t} \bar{S}, A_{L t} L_{t}\right)=G_{t}^{\beta} K_{t}^{\alpha}\left(A_{S t} \bar{S}\right)^{\gamma}\left(A_{L t} L_{t}\right)^{1-\alpha-\gamma} .
$$

Proposition 6 (Macroeconomic Henry George Formula with technological progress). Suppose production can be described by a Cobb-Douglas function with factors of production labor, private and public capital as well as land and assume that production has constant returns to scale in labor, land and private capital. Assume technological progress is balanced between land and labor. Then, on the balanced growth path of the socially optimal allocation, the investment in public capital is related to the land rent as follows:

$$
I_{g}^{*}=\frac{\delta_{g}+g_{s}}{\tilde{\rho}+\delta_{g}+n} \frac{\beta}{\gamma} R .
$$

Proof. Modify the proof of Proposition 1 by performing the same derivation with normalized variables.

Finally, with balanced technological progress the central result about fiscal policy also holds: 
Proposition 7 (Land rent taxation reproduces the social optimum under balanced technological progress). A land rent tax allows to reproduce the social optimum if the land rent is sufficient to finance the optimal public investments.

Proof. Modify the proof of Theorem 2 by performing the same derivation with normalized variables.

\subsection{Beyond the balanced growth path: A historical remark}

Financing the socially optimal level of public investment through land rent taxation needs a land rent that is sufficiently high. Depending on the production function, in an economy that is not on a balanced growth path the land rent and the factor share of land will not be constant, but change with the relative rate of the technological progress in different production factors. While for a Cobb-Douglas production function factor shares are constant, for a CES production function, we derive a condition describing the relationship of the factor shares accruing from land and labor.

Consider the following CES production function (with substitution elasticity $\sigma$ given by $\left.\nu=\frac{\sigma-1}{\sigma}\right)$ :

$$
F\left(K_{t}, A_{S t} \bar{S}, A_{L t} L_{t} ; G_{t}\right)=G^{\gamma}\left(\alpha K_{t}^{\nu}+\beta A_{S t} \bar{S}^{\nu}+(1-\alpha-\beta) A_{L t} L_{t}^{\nu}\right)^{\frac{1}{\nu}} .
$$

Define the factor shares accruing from land and labor as

$$
\frac{F_{S t} \bar{S}}{Y_{t}} \text { and } \frac{F_{L t} L_{t}}{Y_{t}}
$$

respectively.

Proposition 8 (Henry George Claim). For the case of a CES production function with substitution elasticity $\sigma=\frac{1}{1-\nu}$, the factor share accruing from land grows faster than the factor share accruing from labor if and only if either $\nu>0$ and $g_{s}>g_{l}+n$ or $\nu<0$ and $g_{s}<g_{l}+n$.

Proof. One can derive that

$$
\frac{\mathrm{d} \frac{F_{S t} \bar{S} / Y_{t}}{F_{L t} L_{t} / Y_{t}}}{\mathrm{~d} t}=\nu \frac{1-\alpha-\beta-\gamma}{\gamma} \frac{\frac{F_{S t} \bar{S}}{Y_{t}}}{\frac{F_{L t} L_{t}}{Y_{t}}}\left(g_{l}+n-g_{s}\right) .
$$

This result is significant in two ways, both concerning the main conclusion of this article as well as for an understanding of the writings of Henry George. First, the previous proposition modifies the feasibility of the social optimum outside a steady-state: according to Proposition 1, an increasing factor share accruing to land makes reaching the social optimum more 
likely. Numerical simulation of the optimization problems would be required to evaluate the feasibility of the social optimum under such non-balanced technological progress.

Second, Henry George claimed that the factor share accruing from land grows faster than that from labor ${ }^{7}$. While our analysis shows that this is not possible in the steady state or under a Cobb-Douglas production function in general, Proposition 8 indicates when Henry George's claim about the role of the land rent may be true. In particular the condition that $\nu<0$ and $g_{s}<g_{l}+n$ seems to have some plausibility for economic development in the $19^{\text {th }}$ century, while it is less plausible for current developed economies, for which it may be supposed that $\nu>0$, but still $g_{s}<g_{l}+n$.

\section{Discussion}

We discuss modifications and limitations of our results and consider their empirical relevance. First, as many alternative formulations of government investment are considered in the literature, we outline why our results do not essentially change when some other formulations are chosen. Second, we briefly discuss that a crucial limitation of a neoclassical growth model with several stock markets is that due to household homogeneity, there is no trade on these markets. Third, we comment on the empirical relevance of our findings.

\subsection{Alternative models of government spending}

Alternative formulations of government expenditure besides investing into a productive public capital stock have been extensively considered in public economics, for instance productive government flow expenditure or investment into utility-enhancing public or private goods, which each may or may not be congestible (Barro and Sala-I-Martin, 1992; Irmen and Kuehnel, 2009). We limit our discussion to two close variants of the above model that seem most interesting in the specific context of land rent taxation financing public investment: first, the public capital stock may enter the utility function instead of the production function; second, the difference between investment in a public capital stock and productive government flow expenditure is examined.

Concerning the first variant, assume that government expenditure provides private goods entering the individuals' utility function. Then, no simple proportionality between optimal government expenditure and land rent

\footnotetext{
7 "In identifying rent as the receiver of the increased production which material progress gives, but which labor fails to obtain; [...] we have reached a conclusion that has most important practical bearings." (Bk. 4, ch.1 §1) "[...] and wages are forced down while productive power grows, because land, which is the source of all wealth and the field of all labor, is monopolized." (Bk. 6, ch.2, §2) (George, 1920)
} 
as in Propositions 1 or 6 can be derived even with the simplest functional forms, since there is no direct link between the public good and land via the production function anymore. However, in the decentralized model, the households' and firms' optimization problem remains virtually unchanged since $G$ only appears in the utility function and disappears from the production function, but does not become a control variable. Thus, it can be shown that Propositions 2 and 7 still hold ${ }^{8}$.

For the second case, it can be shown that the findings of this study are all valid regardless of whether the productive public good is formulated as a stock (to which the government expenditure continuously adds) or flow (equal to government expenditure), since we only consider steady states or balanced growth paths and no transition phenomena. However, the stock formulation seems preferable as we are chiefly concerned with productivityenhancing public expenditure such as infrastructure provision. Considering a public capital stock is also more convenient for further empirical analyses because of symmetry: for instance, depreciation parameters for public and private capital may be different. Moreover, it is plausible that in developed economies land rents are sufficient to finance socially optimal public investment (see Section 6.3) - but it is doubtful that they can additionally cover government flow spending.

\subsection{Stock markets and household heterogeneity}

Analyzing the dynamics of stock markets for fixed factors of production, such as land, with the neoclassical growth model has severe limitations. (This may have been first noted by Feldstein (1977); see Burgstaller (1994) for a comprehensive overview.) Although a price for land - the present value of all future land rent income - is formed, land will not be traded: the continuum of homogenous agents of this model own an equal share of land, but have no incentive to buy or sell some of it. A neoclassical growth model with land, as introduced above, thus exhibits "partial equilibrium" properties concerning the factor land: for instance, land rent taxation is non-distortionary and the tax falls entirely on the owners of land, although this is not generally the case (Feldstein, 1977). There is in particular no "portfolio effect": households have no incentive to invest more in capital when a land rent tax is introduced. Our companion paper (Edenhofer et al., 2013) explores the social optimality of land rent taxation if heterogeneous households acquire more land as they get older by means of a continuous overlapping generations model. In such a model, which exhibits suboptimal capital accumulation, a portfolio effect is present because when land is taxed, households invest into other assets, notably private capital. Thus land rent taxation is distortionary, but beneficial. The results of the present study

\footnotetext{
${ }^{8}$ Proposition 4 is pointless if $G$ generates no profits, while Proposition 8 remains unaffected.
} 


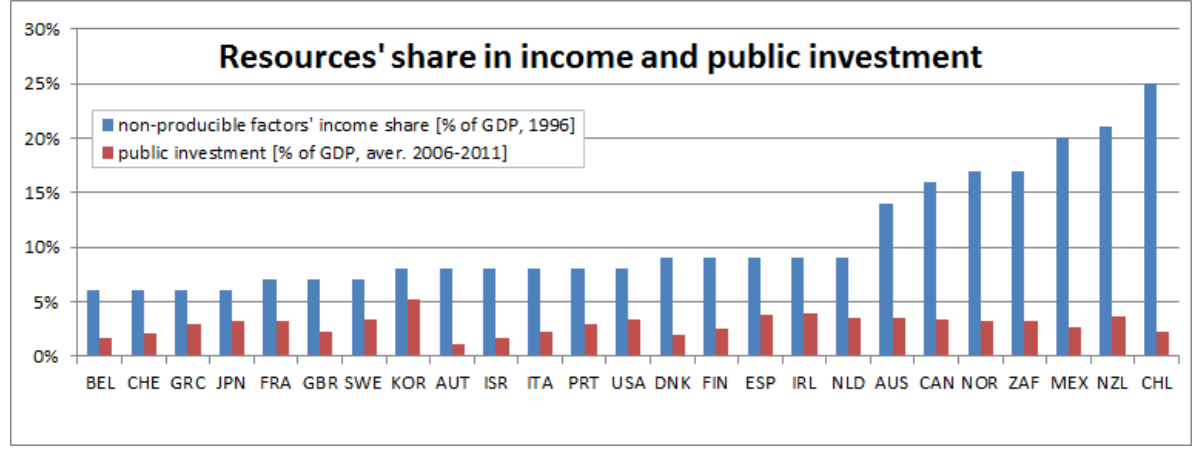

Figure 1: Income shares of non-producible factors (Caselli and Feyrer, 2007) and public investment (OECD, 2013), ISO3 country codes.

can be reproduced in such a framework with some minor modifications due to the demographic structure.

More generally, as long as the unregulated equilibrium exhibits underaccumulation in private capital the conclusions of the present study hold in frameworks in which such a portfolio effect exists. Only if overaccumulation prevails in an economy, the portfolio effect may create again a trade-off between the welfare loss caused by the land tax and the benefits from public investment.

\subsection{Empirical relevance}

In practice, fixed factor rents often exceed funding needs for public capital stocks considered here, and are thus highly relevant for financing government expenditure in general. Figure 1 illustrates this by reproducing actual public investment shares and non-producible factor income shares for 25 (mostly OECD) countries. We summarize some empirical findings, first on public investment needs and then on rents.

Regarding the investment needs of industrialized countries, maintaining the infrastructure and adapting it to the challenges of climate change (Davis et al., 2010) translates into significant shares of government spending: The OECD reports public investment shares averaged over 2006 to 2011 for 34 countries that range between $1.1 \%$ (Austria) and $5.22 \%$ (South Korea) of GDP. The investment needs in poorer countries are highlighted by data from the World Bank (2009) showing that access to basic utility services such as water, sanitation and electricity in low-income countries was $65 \%, 36 \%$ and $23 \%$, respectively, and still only $92 \%, 72 \%$ and $97 \%$ for upper-middle income countries. Estache and Fay (2007) estimated overall infrastructure investment and maintenance expenditure needs between 2005 and 2015 for low, lower-middle and upper-middle income countries to be 7.5, 6.3 and 3.1 percent of GDP, respectively, just to meet increasing demand due to 
projected growth. While these actual or projected spending figures may not be optimal by some welfare criteria, they show the order of magnitude and the larger public investment needs in poorer countries lacking the most basic infrastructure.

Regarding the fixed factor rents, Caselli and Feyrer (2007) estimate income shares of non-producible factors such as land and natural resources for 51 countries $^{9}$ and find values ranging from $6 \%$ in Belgium to $47 \%$ in Ecuador, with a median of $14 \%$. Also, non-producible factors tend to be more important for poorer countries.

This indicates that fixed factor rents can be assumed to be of a magnitude that is at least comparable to that of infrastructure spending needs.

\section{Conclusion}

This study set out to determine how public investment can be financed by a tax on the rent of fixed factors such as land. It was proved that if the land rent is sufficiently high, the social optimum can be implemented by using the tax revenue for investment into a productive public capital stock. This result is a macroeconomic analogue of the Henry George Theorem from urban public finance: the socially optimal public investment can be financed by taxing rents, whereas the usual condition of optimal population size in a static model is replaced by optimal capital accumulation in the dynamic context. The main theoretical result of this study is robust under a variety of different assumptions: (i) technological progress in land and labor compatible with balanced growth, (ii) profit-making firms instead of land rents earned by households, (iii) utility-enhancing public capital or government flow spending, (iv) underaccumulation in public capital due to for instance overlapping generations. It was verified that for OECD countries, land rents are significantly higher than current public investment, so that our result constitutes an empirically plausible method for financing public investment.

\section{Acknowledgments}

We thank Max Franks for useful comments. Financial support from the Michael-Otto-Stiftung for the Chair Economics of Climate Change at TU Berlin is gratefully acknowledged. Linus Mattauch thanks the German Na-

\footnotetext{
${ }^{9}$ Caselli and Feyrer (2007) use "Proportions of different types of wealth in total wealth" (p.547): these show that although subsoil resources matter for some countries (with a mean wealth share of $10.5 \%$ and a standard deviation of 16.4 , compared to a $34.8 \%$ mean share of land-related wealth), land wealth is relatively more important in most cases (the median wealth share of subsoil resources is only $1.5 \%$; compare this to a $23.5 \%$ median share of land-related wealth). Moreover, the dataset of that study excludes countries in which fossil fuel extraction is a main income source, such as countries on the Arabic Peninsula.
} 
tional Academic Foundation for financial support through a doctoral scholarship.

\section{References}

Acemoglu, D., 2008. Introduction to modern economic growth. Princeton University Press.

Agénor, P.-R., 2013. Public Capital, Growth and Welfare. Analytical Foundations for Public Policy. Princeton University Press.

Arnott, R. J., 2004. Does the Henry George theorem provide a practical guide to optimal city size? American Journal of Economics and Sociology 63(5), 1057-1090.

Arnott, R. J., Stiglitz, J. E., 1979. Aggregate land rents, expenditure on public goods, and optimal city size. Quarterly Jounral of Economics 93(4), 471-500.

Atkinson, A. B., Stiglitz, J. E., 1980. Lectures on public economics. McGrawHill.

Barro, R. J., 1990. Government spending in a simple model of endogenous growth. Journal of Political Economy 98(5), 103-125.

Barro, R. J., Sala-I-Martin, X., 1992. Public finance in models of economic growth. The Review of Economic Studies 59(4), 645-661.

Bloom, D. E., Canning, D., Sevilla, J., 2004. The effect of health on economic growth: theory and evidence. World Development 32(1), 1-13.

Burgstaller, A., 1994. Property and prices: Toward a unified theory of value. Cambridge University Press.

Calvo, G. A., Kotlikoff, L. J., Rodriguez, C. A., 1979. The incidence of a tax on pure rent: A new (?) reason for an old answer. Journal of Political Economy 87(4), 869-874.

Caselli, F., Feyrer, J., 2007. The marginal product of capital. Quarterly Journal of Economics 122(2), 535-568.

Creel, J., Poilon, G., 2008. Is public capital productive in europe? International Review of Applied Economics 22(6), 673-691.

Davis, S. J., Caldeira, K., Matthews, H. D., 2010. Future CO2 emissions and climate change from existing energy infrastructure. Science 329(5997), $1330-1333$. 
Edenhofer, O., Mattauch, L., Siegmeier, J., 2013. Hypergeorgism: When is rent taxation as a remedy for insufficient capital accumulation socially optimal? CESifo Working Paper Series 4144.

Estache, A., Fay, M., 2007. Current debates on infrastructure policy. Worldbank Policy Research Working Paper 4410.

Feldstein, M. S., 1977. The surprising incidence of a tax on pure rent: A new answer to an old question. Journal of Political Economy 85(2), 349-360.

Foley, D. K., Michl, T. R., 1999. Growth and Distribution. Harvard University Press.

Fu, S., 2005. Essays on urban agglomeration economies. Ph.D. thesis, Boston College.

George, H., 1920. Progress and Poverty: An Inquiry into the Cause of Industrial Depressions and of Increase of Want with Increase of Wealth: The Remedy. Doubleday, Page \& Co., 4th edition.

Glomm, G., Ravikumar, B., 1992. Public versus private investment in human capital: endogenous growth and income inequality. Journal of Political Economy 100(4), 818-834.

Gramlich, E. M., 1994. Infrastructure investment: a review essay. Journal of Economic Literature 32, 1176-1196.

Groth, C., 2011. Lecture notes in macroeconomics. mimeo, available at: http://www.econ.ku.dk/okocg/VM/VM-general/Material/ChaptersVM.htm, retrieved 2013/04/10.

Irmen, A., Kuehnel, J., 2009. Productive government expenditure and economic growth. Journal of Economic Surveys 23(4), 692-733.

Kawano, M., 2012. Henry george theorem in a dynamic framework without accumulation of public goods. Kwansei Gakuin University School of Economics Discussion Paper 92.

Lehmann, P., Creutzig, F., Ehlers, M.-H., Friedrichsen, N., Heuson, C., Hirth, L., Pietzcker, R., 2012. Carbon lock-out: Advancing renewable energy policy in europe. Energies 5(2), 323-354.

Mattauch, L., Creutzig, F., Edenhofer, O., 2012. Avoiding carbon lockin: Policy options for advancing structural change. Climatecon Working Paper 1-2012.

OECD, 2013. Economic policy reforms: Going for growth 2013. Policy report, table "Public investment: Percentage of GDP", 
DOI:http://dx.doi.org/10.1787/growth-2013-graph177-en, retrieved 2013/04/09.

Romer, P. M., 1990. Endogenous technological change. Journal of Political Economy 98(5), S71-S102.

Romp, W., De Haan, J., 2007. Public capital and economic growth: A critical survey. Perspektiven der Wirtschaftspolitik 8(S1), 652.

Stiglitz, J., 1977. The theory of local public goods. In: Feldstein, M., Inman, R. (Eds.), The Economics of Public Services, MacMillan, London.

Unruh, G. C., 2000. Understanding carbon lock-in. Energy policy 28(12), 817-830.

World Bank, 2009. World development indicators 2009. database, available at http://databank.worldbank.org/data/views/variableselection/ selectvariables.aspx? source=world-development-indicators, retrieved $2013 / 03 / 25$.

Zagler, M., Dürnecker, G., 2003. Fiscal policy and economic growth. Journal of Economic Surveys 17(3), 397-418. 